\title{
AMETROPIAS E PRESBIOPIA
}

\author{
AMETROPIAS AND PRESBYOPIA
}

Harley E. A. Bicas

Docente do Departamento de Oftalmologia e Otorrinolaringologia da Faculdade de Medicina de Ribeirão Preto da Universidade de São Paulo.

CORRESPONDÊNCIA: Departamento de Oftalmologia e Otorrinolaringologia da Faculdade de Medicina de Ribeirão Preto - Campus Universitário - CEP: 14048-900 - Ribeirão Preto - SP. Fax: (016) 633-0186.

BICAS HEA. Ametropias e presbiopia. Medicina, Ribeirão Preto, 30: 20-26, jan./mar. 1997.

RESUMO: O sistema óptico de um olho normal, com as características fundamentais de seus componentes e suas interrelações, é definido na distinção de emetropia e das ametropias (miopias e hipermetropias) axiais ou refracionais. Os procedimentos de estudo dos estados ópticos dos olhos (refratometria) são sintetizados, comentando-se outros resultados que podem deles advir (astigmatismos, anisometropias). É também analisada a capacidade de mudança do poder focal do olho (acomodação) e sua perda progressiva, com a idade (presbiopia). Sintomas e sinais decorrentes da presbiopia e das ametropias (reduções de acuidade visual, dores e irritações oculares, cefaléia, aversões a esforços visuais, hordéolos, estrabismos, ambliopias, etc.), respectivos tratamentos e prognósticos de evolução são também abordados.

UNITERMOS: Miopia. Hiperopia. Astigmatismo. Anisometropia. Acomodação Ocular. Presbiopia.

Uma das funções fundamentais do olho é a de propiciar a formação de imagens sobre a retina. Há, para isso, um sistema óptico conjugado, não muito complexo, mas de alta eficiência e que pode ser sintetizado como composto por duas lentes básicas: a córnea (K) e o cristalino (R), além de um diafragma que controla a entrada da luz (a íris, com o orifício pupilar em seu centro). Costuma-se fazer uma analogia entre o olho e uma câmara fotográfica comum: a esclera, a camada envoltória do olho, forma a câmara propriamente dita; a retina é o filme sobre o qual deve ser focalizada a imagem do objeto a ser fotografado (visto); a íris (para o olho) é o diafragma com o qual se controla a abertura (na câmara fotográfica). No caso do sistema óptico, o do olho é composto por duas lentes: uma de poder dióptrico fixo $(\mathrm{K})$ e a outra de valor reajustável $(\mathrm{R})$, enquanto na câmara fotográfica há apenas uma lente, de poder dióptrico constante (equivalendo, pois, à córnea, K), mas um mecanismo com o qual se pode fazer variar a distância focal do sistema (equivalendo à função desempenhada, no olho, pelo cristalino R). A única diferença, pois, é a de que na câmara fotográfica a distância focal é mudada pela variação real da posição entre a lente e o filme; enquanto, para o olho, a distância entre a córnea e a retina é constante, variando o poder dióptrico do sistema pela variação do poder focal do cristalino.

O olho tem, pois, um comprimento axial constante, mas variados poderes focais, em função do ajustado pelo valor dióptrico do cristalino. Em certos casos, porém, esse ajustamento não é possível; em outros, sim, mas com sintomas. Em outros, enfim, o ajustamento é bom e sem sintomas. Como, então, definir o que é adequado? 


\section{O SISTEMA ÓPTICO NORMAL. A EMETROPIA}

A córnea é uma lente convexo-côncava, menos curva em sua face anterior (raio de curvatura de $7,7 \mathrm{~mm}$ ) que em sua face posterior (raio de curvatura de aproximadamente $6,8 \mathrm{~mm}$ ), entre as quais o índice de refração é 1,376 . No ar, isso equivale a um menisco divergente, com poder focal igual a -5,5 D. Separando, entretanto, o ar $(\mathrm{n}=1,000)$ do humor aquoso ( $\mathrm{n}=1,336)$, a córnea transforma-se numa poderosa lente convergente, com poder focal de $+43 \mathrm{D}$. A espessura da córnea é de cerca de $0,5 \mathrm{~mm}$ em seu centro, mas tal valor é quase irrelevante para cálculos ópticos. Geralmente, então, se a representa por um dióptrico único $(\mathrm{r}=7,8 \mathrm{~mm})$, separando o ar e o aquoso.

A uns 3,6 mm atrás do vértice da córnea, está o pólo anterior do cristalino. Este já é uma lente mais complexa, na qual podem ser distinguidas uma camada cortical anterior e uma posterior (com índices de refração iguais a 1,386) envolvendo um núcleo (com $\mathrm{n}=1,406$ ). Daí resultaria uma lente biconvexa de altíssimo poder focal (no ar, mais de $100 \mathrm{D}$ ) mas que, separando o humor aquoso do corpo vítreo (com índices de refração iguais a 1,336, muito próximos dos das camadas corticais), tem seu poder dióptrico reduzido a cerca de umas $19 \mathrm{D}$, em repouso. A característica flexível do cristalino propicia-lhe o aumento de suas curvaturas, principalmente a anterior, por contração do músculo ciliar, daí resultando um aumento de seu poder focal, processo esse conhecido como acomodação.

Em repouso, então, o poder focal do sistema óptico ocular (E) pode ser calculado por:

$E=K+R-K \cdot R \cdot d / n \cong 43+19-43 \cdot 19 \cdot 7 \cdot 10^{-3} / 1,336 \cong 59$,

onde d é a distância entre os pontos principais das lentes K e R (o segundo e o primeiro, respectivamente), equivalente a uns $7 \mathrm{~mm}$ e $\mathbf{n}$ o índice de refração do meio entre elas.

Correspondendo a esse poder dióptrico "normal", a distância focal posterior do sistema seria de uns $24,5 \mathrm{~mm}$, exatamente a posição de uma retina, num olho de tamanho "normal". Define-se então aquilo que é conhecido como emetropia (do grego "eu", "boa"; "metros", medida; "ops", olho: olho de boa medida) normal. Em princípio, pode parecer reverberativo ou tautológico falar de uma emetropia (normalidade óptica) normal. Mas assim não é: um poder dióptrico menor (por exemplo, $55 \mathrm{D}$ ) poderia estar opticamente compensado por um comprimento axial maior (cf. Figura $1 \mathrm{Lb}$ ), ou um poder dióptrico de lentes mais refringentes (por exemplo, $62 \mathrm{D}$ ), poderia estar compensado por um comprimento axial menor (cf. Figura $1 \mathrm{Ca}$ ), ambas condições também configuradas como de emetropia (compensada).

Em suma: emetropia é uma condição de adequação entre o comprimento axial de um olho e o poder de refringência de seu sistema óptico. Com isso, perde completamente o significado a mensuração isolada do poder óptico absoluto do olho (valores dióptricos), antes interessando conhecer-lhe o poder óptico relativo (valores dióptricos em função do comprimento axial).

\section{AMETROPIAS}

De fato, podem ocorrer inadequações, tanto as de comprimento axial para um poder dióptrico em princípio "normal" (isto é, $59 \mathrm{D}$ ), como as de poder dióptrico, para um comprimento axial em princípio "normal" (isto é, cerca de $24,5 \mathrm{~mm}$ ). As inadequações ópticas são chamadas ametropias (do grego, o prefixo a, negação), isto é: "com falta de (boa) medida do olho". Quando o erro se dá pela inadequação do comprimento do eixo ântero-posterior do olho, as ametropias são classificadas como axiais; quando por defeito do sistema de refração ocular, como ametropias refracionais ou de refringência. Se o defeito faz com que haja um excesso de refringência relativamente ao comprimento do eixo ocular ântero-posterior, diz-se haver miopia. Quando há insuficência de refração para um dado comprimento axial ocular longitudinal, fala-se em hipermetropia. Assim, será possível toda uma série de combinações, como miopia axial pura (Figura $1 \mathrm{Ln}$ ), hipermetropia axial pura (Figura $1 \mathrm{Cn}$ ), miopia refracional pura (Figura $1 \mathrm{Na}$ ) ou combinada (Figura $1 \mathrm{La}$ ), hipermetropia refracional pura (Figura $1 \mathrm{Nb}$ ) ou combinada (Figura $1 \mathrm{Cb}$ ) e, até, miopia com olho "curto", hipermetropia com olho "longo", miopia com baixo poder refracional e hipermetropia com alto poder refracional, dependendo de outras combinações: embora não mostradas na Figura 1, estariam em posições à direita de $\mathrm{Ca}$, à esquerda de $\mathrm{Lb}$, abaixo de $\mathrm{Lb}$, acima de $\mathrm{Ca}$, se o gráfico fosse completado com colunas à esquerda (baixíssima refringência ocular) e à direita (altíssima refringência ocular) e com fileiras horizontais acima (olho curtíssimo) e abaixo (olho longuíssimo). 
Resulta, pois, que ao oftalmologista interessa conhecer a adequação (relativa) do sistema óptico ao comprimento axial, o que pode ser facilmente determinado, com objetividade, pelo método conhecido como refratometria.

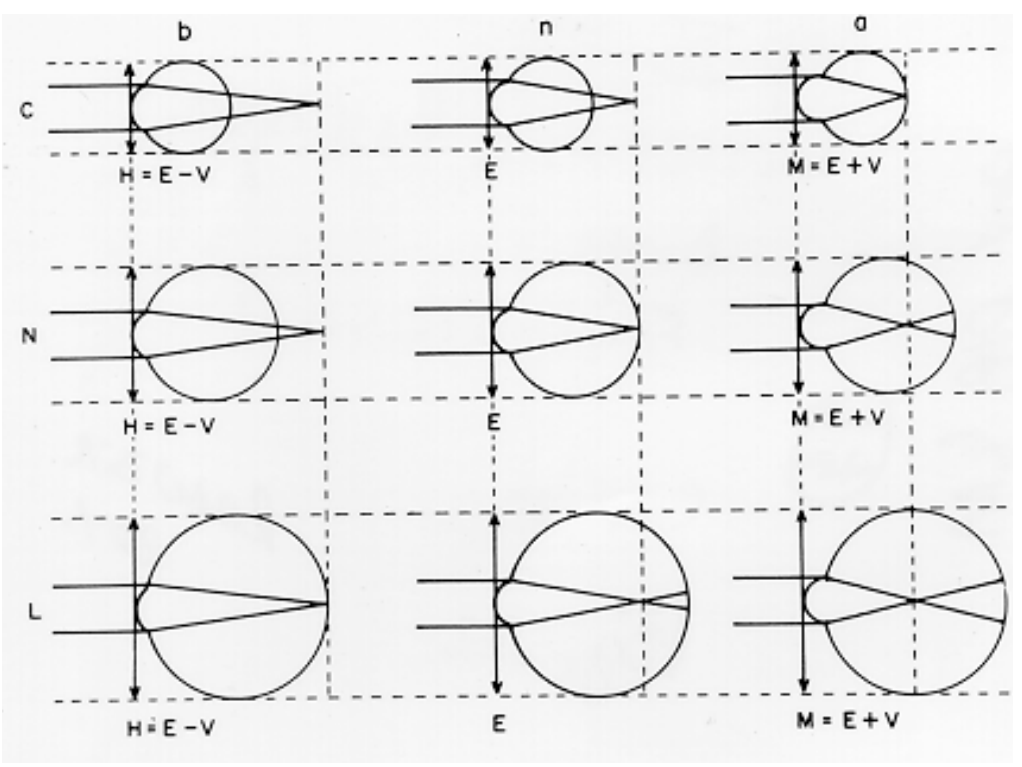

Figura 1 - Relações entre refringência ocular baixa (b, ou H = E - V), normal $(n=E)$, ou alta (a, ou $\mathrm{M}=\mathrm{E}+\mathrm{V}$ ) e eixo ocular longitudinal (comprimento ocular) curto (C), normal (N) ou longo (L). Se a retina estiver no plano focal posterior, há emetropia (Ca, $\mathrm{Nn}, \mathrm{Lb})$. Havendo formação das imagens atrás da retina, há hipermetropia axial $(\mathrm{Cn})$, refracional $(\mathrm{Nb})$ ou combinada $(\mathrm{Cb})$. Havendo formação das imagens adiante da retina, há miopia axial $(\mathrm{Ln})$, refracional $(\mathrm{Na})$ ou combinada $(\mathrm{La})$. no olho (são, pois, lentes "positivas" ou "convergentes" para o caso da hipermetropia). Com esse novo conjunto, repetir-se-á a prova. Se a lente colocada houver sido insuficiente, continuar-se-á com o diagnóstico de "hipermetropia" para o sistema (olho mais lente) e uma, de maior poder dióptrico, deve ser novamente testada. Se a lente colocada houver sido excessiva, mudar-se-á agora o diagnóstico para "miopia" do sistema, o que significa que outra de menor valor (positivo) deverá ser testada. Quando se faz o diagnóstico de "emetropia" do conjunto, isto é, com uma lente que produza o "ponto de viragem" de hipermetropia para miopia, ter-se-á, na testada, o valor da que objetivamente corrige o vício de refração da pessoa.

Obviamente, para que não ocorram variações do poder dióptrico do olho durante o exame, convém que o músculo ciliar esteja paralisado, o que se consegue com a instilação de colírios cicloplégicos. Tais colírios, parassimpaticolíticos, produzem também midríase (dilatação pupilar) mas esse não é o efeito primordialmente buscado.

\section{REFRATOMETRIA}

Sem buscar descrever a óptica do método refratométrico, que pode ser achada em livros que a analisam ${ }^{1}$, basta a referência de que um feixe luminoso, incidindo sobre a retina do examinado e movido de um lado a outro, dará (se a condição de observação equivalesse à do examinador no infinito):

a) num olho míope, um reflexo (da luz na retina) movendo-se em sentido contrário ao da luz incidente;

b) no hipermétrope, um reflexo com movimento no mesmo sentido do da luz incidente;

c) no emétrope, não será notado qualquer movimento, mas, uma iluminação difusa da retina.

Notando-se, pois, por exemplo, um movimento "a favor" do da luz incidente (hipermetropia) proceder-se-á à colocação de lentes diante do olho, que tendam a corrigir-lhe a relativa insuficiência de refração, produzindo convergência do feixe luminoso que entra

\section{ASTIGMATISMO}

Se o estudo refratométrico for feito inicialmente para um plano vertical e, depois, para um horizontal do olho, os valores dióptricos podem ser diferentes. Nesse caso, diz-se haver um astigmatismo que, dependendo da combinação de resultados, pode ser:

a) hipermetrópico composto, quando nos dois eixos houver hipermetropia (com valores diferentes, obviamente);

b) hipermétropico simples, quando apenas num eixo houver hipermetropia, sendo o outro eixo emétrope;

c) misto, quando houver miopia num eixo e hipermetropia no outro;

d) miópico simples, quando num eixo houver miopia e, no outro, emetropia;

e) miópico composto, quando nos dois eixos houver miopia (com valores diferentes). 
Os valores do astigmatismo são, então, os das diferenças dióptricas entre os eixos.

Diz-se que o astigmatismo é "na regra", quando o meridiano ocular vertical for mais refringente (mais miópico ou menos hipermetrópico) que o horizontal. Esse tipo de astigmatismo é o mais comumente encontrado, sendo isso atribuído a uma curvatura mais acentuada do meridiano vertical da córnea, suposta como causada pelo simples peso da pálpebra superior sobre o olho. O astigmatismo será dito "contra-a-regra", quando o meridiano ocular de maior refringência for o horizontal.

O astigmatismo pode ser inclinado, isto é, os eixos de maior e menor refringência não coincidirem com os meridianos vertical e, ou horizontal do olho. Há ainda um tipo de astigmatismo "bioblíquo", em que os eixos de maior e menor refringência não são ortogonais. Mas isso é mais raro. Finalmente, no astigmatismo irregular, não haveria qualquer padrão de variação dióptrica, quando os diferentes meridianos oculares forem considerados.

\section{ACOMODAÇÃO. PRESBIOPIA}

Pela lei dos focos conjugados, se um objeto se aproxima do pólo anterior do olho, sua imagem se distancia desse ponto (com movimentos no mesmo sentido). Assim, para um míope, a imagem aproximar-se-á da retina e nela chegará, quando o objeto estiver próximo ao olho, no chamado "ponto remoto". Valores de acomodação, como os de ametropias, são dados em dioptrias, uma unidade óptica equivalente ao inverso de uma distância (focal), quando medida em metros. Assim, um míope de $-2 \mathrm{D}$ terá seu ponto remoto equivalente à distância de $0,5 \mathrm{~m}(=1 / 2)$. Um míope de $-8 \mathrm{D}$ terá seu ponto remoto a $0,125 \mathrm{~m}(=1 / 8)$.

Para o hipermétrope, o ponto remoto é "negativo", está "atrás" da retina. A aproximação do objeto ao olho fará com que a imagem se distancie ainda mais da retina. O míope, não podendo "desacomodar" (isto é, relaxar o músculo ciliar, já em repouso), tem acomodação nula para seu ponto remoto e só passa realmente a exercê-la em aproximações maiores do objeto. Para o hipermétrope, dar-se-á o oposto: mesmo para objetos no infinito ele já é obrigado ao exercício da acomodação, compensando seu vício refratométrico, mas fará esforços ainda maiores quando o objeto se aproximar. Em princípio, pode ser usada a fórmula: $\mathbf{A}=\mathbf{V}-\mathbf{L}+\mathbf{1 / d}(*)$, em que $\mathbf{V}$ é o vício de refração (positivo nas hipermetropias e negativo nas miopias), $\mathbf{U}$ a lente eventualmente usada (a que normalmente compensa o vício de refração tem o mesmo valor deste, $\mathbf{V}=\mathbf{U}$ ) e $\mathbf{d}$ a distância (em metros) a qual um objeto está. Por exemplo: um hipermétrope de $4,5 \mathrm{D}(\mathrm{V}=+4,5)$ usando uma lente de $+2 \mathrm{D}$, que lhe corrige parcialmente o vício refratométrico $(\mathrm{U}=+2)$ terá, para um objeto a $20 \mathrm{~cm}(\mathrm{~d}=0,2 \mathrm{~m})$ a necessidade acomodativa de $\mathrm{A}=4,5-(+2)+5=7,5 \mathrm{D}$.

A capacidade acomodativa máxima de uma pessoa pode ser determinada pelo processo conhecido como do "ponto próximo de acomodação" (P.P.A.). Por ele se avalia a menor distância (d) a que se pode aproximar um objeto, de modo que minúcias de suas formas cheguem ainda a ser percebidas (por exemplo, leitura de um texto de tipos gráficos de tamanhos bem reduzidos, como os de Bíblias pequenas). Claro que se houver vício refratométrico presente $(\mathbf{V})$ e, ou lente em uso (U) a fórmula já apresentada deve ser usada, para o cálculo da acomodação máxima.

Em crianças muito novas, valores de acomodação de umas $15 \mathrm{D}$ poderiam ser exercidos. Mas, progressivamente, eles vão se reduzindo, em todas as pessoas (hipermétropes, emétropes ou míopes) de modo que, ao redor dos 40 anos, apenas umas $4 \mathrm{D}$ ou $5 \mathrm{D}$ de acomodação estariam ainda disponíveis; e mais adiante, por volta de uns 60 anos de idade, toda capacidade acomodativa chega a zero. Claro que existem variações individuais, fazendo com que certas pessoas apresentem, nas mesmas idades, capacidades acomodativas pouco maiores, ou menores; ou que, reciprocamente, mesmas capacidades acomodativas sejam alcançadas em idades diferentes para cada pessoa. De qualquer forma, a redução do processo acomodativo, a presbiopia (do grego "presbis", velho, "ops", olho) é um processo universal e irreversível.

Assim, para o exemplo antes referido, o exercício da acomodação de 7,5 D será, ou não, possível, na dependência da idade do paciente. Um jovem poderá consegui-la, mas uma pessoa de 45 anos já não alcançará fazê-la.

$\left(^{*}\right)$ Embora bem suficiente como primeira aproximação e para boa parte dos cálculos sobre acomodação, essa fórmula não é exata, ao não considerar a chamada "distância vértice" (s), entre o primeiro ponto principal do olho (cerca de 1,6 mm atrás da face anterior da córnea, num olho de refração normal) e o segundo ponto principal de uma lente de óculos (U), geralmente colocada a uns $13 \mathrm{~mm}$ adiante daquele ponto. Usa-se, então $A=[D-U(1-s D)][1-s U(1-s D)]^{-1}+L_{0} /\left(1-s L_{0}\right)\left(B_{i c a s}^{2}\right)$, onde $D=1 / d$ e $L_{o}$ a lente que corrige o vício de refração $V$, sendo $V=L_{0}\left(1-s L_{0}\right)$. 


\section{SINTOMAS E SINAIS}

O míope não pode "desacomodar", isto é, não pode relaxar seu músculo ciliar e aplainar as curvaturas do cristalino, a partir de sua posição de repouso. Por isso, não vê bem "para longe", ou melhor, além de seu ponto remoto. Míopes de -2 D, -5 D e -10 D terão, para o infinito, as acomodações equivalentes a seus vícios refratométricos, isto é, necessidades de ajustamento óptico de $-2,-5$ e $-10 \mathrm{D}$ que, como não satisfeitas pelas respectivas desacomodações (sinais negativos dessa função), equivalerão a prejuízos de acuidade visual (maior no míope de $10 \mathrm{D}$, menor no de 2 D). Para a distância de 1 metro (1 D) as necessidades (não compensadas) serão, respectivamente, $-1,-4$, e -9 D, ou seja, pouco menores: a nitidez discriminativa ainda não é possível, mas a falta dela já é menor. Para $0,5 \mathrm{~m}$, as acomodações necessárias serão $0,-3$ e -8 e, pois, o míope de $-2 \mathrm{D}$, em seu ponto remoto $(50 \mathrm{~cm}=2 \mathrm{D})$ estará vendo bem, enquanto os outros ainda não. A $25 \mathrm{~cm}$, as necessidades seriam, respectivamente, $-2+4=+2 \mathrm{D}$ (acomodação a ser exercida, dependendo da idade), $-5+4=-1 \mathrm{D}$ (ajustamento óptico ainda não possibilitado, dando prejuízo de acuidade visual para essa distância) e $-10+4=-6 \mathrm{D}$ (idem). Obviamente, o míope de $-5 \mathrm{D}$ só teria bom ajustamento visual a $20 \mathrm{~cm}$ (seu ponto remoto) ou a distâncias menores (devendo então acomodar) e o míope de $-10 \mathrm{D}$ teria boa acuidade visual apenas a $10 \mathrm{~cm}$ (seu ponto remoto) ou a distâncias menores. A regra de que o míope vê mal para longe está correta, mas a de que vê "bem" para perto, não: "perto" é um termo que não define distância (da qual depende a resolução óptica) nem a acomodação (que é função da idade).

O hipermétrope pode exercer a acomodação. $\mathrm{O}$ de $+1 \mathrm{D}$ deverá fazer tal ajustamento $(1 \mathrm{D})$ já para um objeto no infinito e adicionar mais esforço acomodativo à medida em que aquele se aproxima. Por exemplo, a $33 \mathrm{~cm}$, a acomodação que, num emétrope, seria de $3 \mathrm{D}$, deverá chegar, nele, a 4 D. Ora, a compensação acomodativa para longe (1 D) pode ser feita na infância e mocidade, mas não na velhice, o que significa que a necessidade de uso de lentes corretoras (para longe) não surgirá no começo da vida, mas, sim, mais adiante. Obviamente, para a leitura ( $\cong 33 \mathrm{~cm}$ de distância) as dificuldades serão sentidas antes que as de um emétrope. Já outro hipermétrope de $4 \mathrm{D}$, deverá exercer essa acomodação (4 D) para objetos muito distantes, aumentando-a para os mais próximos; ora, manter uma acomodação constante de 4 ou mais dioptrias não é fácil, até para um jovem, mesmo que a capacidade máxima de acomodação seja maior que tal valor. Tal hipermétrope poderá, então, compensar seu defeito óptico, mas à custa de sintomas: dores nos olhos e, ou cefaléia (principalmente ao final do dia, relacionando os sintomas à leitura e esforços visuais para ver objetos próximos), aversão às circunstâncias de maior esforço (um mecanismo de defesa; mas, geralmente, interpretado como "preguiça", desinteresse, etc., levando a maus rendimentos escolares ou equivalentes), "borramentos" da visão (por eventual relaxamento da acomodação, cansada, na fixação a um objeto), irritações (hiperemia, prurido) nos olhos e até hordéolos, principalmente em crianças, etc. É bem provável que uma pessoa, embora não consiga manter constantemente um determinado nível de esforço acomodativo chegue, perfeitamente, a exercê-lo em circunstâncias como as de "provas de esforço" (e.g., os testes de acuidade visual). Em suma, o bom desempenho num teste de acuidade visual não significa, necessariamente, que a pessoa seja emétrope, não elimina a possibilidade de ela possuir uma hipermetropia até relativamente alta $\mathrm{e}$ causadora de sintomas. Em casos de dúvidas (queixas !) o exame refratométrico deverá ser realizado.

O exercício da acomodação é mediado pelo III nervo cranial, também subsidiário da estimulação à convergência, numa sincinesia. Resulta, então, que valores muito altos de hipermetropia, ou defeitos nessa sincinesia (uma alta convergência suscitada pela inervação necessária à obtenção de uma acomodação, ainda que reduzida), darão convergências dos eixos visuais, mesmo quando não necessárias: aparecerá um estrabismo convergente. Chamado estrabismo acomodativo, por estar relacionado ao exercício da acomodação, é um quadro relativamente freqüente, aparecendo em crianças com aproximadamente 2 a 4 anos de idade. Um mecanismo análogo, mas por falta de acomodação, em míopes, explica a insuficiência de convergência (para objetos próximos) e, pois, uma tendência a desvios oculares (estrabismos) divergentes.

No astigmatismo, a acomodação pode também ser exercida; mas como é global, isto é, modifica o poder dióptrico de todos os meridianos oculares, a diferença entre o de maior e o de menor refringência continuará inalterada. A redução na capacidade visual discriminativa de formas (acuidade visual) será uma consequiência. Nos astigmatismos, a posição de optotipos costuma suscitar respostas desiguais: acertos de informação posicional para uma orientação (por exemplo, horizontal) e erros nas apresentações complementares (no caso, verticais). Essa seletividade poderia ser objeto de ajustamento acomodativo, em casos de 
astigmatismos hipermétrópicos (simples ou compostos) nos quais se poderia ter, até, um bom desempenho no teste de acuidade visual.

Quando a ametropia é muito alta, fazendo com que uma estimulação óptica adequada da retina não seja possível, haverá um prejuízo no desenvolvimento e estruturação do sistema visual, levando a um defeito funcional chamado ambliopia. A manifestação da ambliopia é, principalmente, a de baixa capacidade visual resolutiva de formas, mesmo que sua causa original seja corrigida. Isto é, ainda que a ametropia seja apropriadamente compensada por lentes, persistirá uma redução de acuidade visual, por falta do desenvolvimento de conexões neuronais (aprendizagem discriminativa) adequadas. O grave é que tal processo só pode ser eficazmente evitado e tratado nas primeiras idades, tornando-se irreversível já por volta de uns 8 a 10 anos de vida.

Outra causa de ambliopia é a anisometropia, a diferença de valores ópticos dos dois olhos.

\section{ANISOMETROPIA}

Do grego “an" (não), "iso" (igual), é a condição de desigualdade das medidas ópticas oculares. Por exemplo, se um olho tiver uma hipermetropia de $+2 \mathrm{D}$ e o outro uma de $+6 \mathrm{D}$, diz-se haver uma anisohipermetropia. No caso de olhos com miopias de, por exemplo, -1 D e -6,5 D, diz-se haver uma anisomiopia. Pode, até, haver uma anisoemetropia (por exemplo, condições Ca e Lb, Figura 1). Nestes casos, o tamanho da imagem de um objeto, nas retinas, será diferente (aniseiconia), circunstância que pode também ocorrer na correção óptica (isometropização) das anisometropias, produzindo dificuldades de fusão binocular.

\section{TRATAMENTO}

As lentes de óculos ou as de contato compensam o defeito óptico, mas como este é causado por uma inadequação estrutural do olho (curvaturas dióptricas excessivas ou insuficientes relativamente ao tamanho do olho), não o eliminam. As lentes que corrigem as hipermetropias são as "esféricas positivas". As que corrigem as miopias são as "esféricas negativas". Para os astigmatismos hipermetrópicos simples, as correções são dadas pelas "cilíndricas positivas" e para os astigmatismos miópicos simples, as "cilíndricas negativas". Para os astigmatismos compostos e mistos, em que duas curvaturas dióptricas diferentes são necessárias, fala-se em lentes "tóricas".
O uso de lentes de óculos não tem restrições, enquanto o das de contato pode ser contra-indicado em afecções de conjuntiva e córnea, assim como em outras condições (olho "seco", atividades em ambientes poluídos, etc.). Do ponto de vista óptico, lentes convencionais produzem imagens de tamanhos menores que as das lentes de contato na correção das miopias (o que pode ser uma desvantagem para as primeiras) mas maiores nas hipermetropias. Lentes convencionais negativas aumentam o campo visual dos míopes, as positivas diminuem o dos hipermétropes, enquanto as de contato não trazem modificações nesse aspecto. Para que não ocorra aniseiconia na correção óptica das anisometropias, a solução técnica ideal seria a de uso de lentes convencionais nas anisometropias axiais e de lentes de contato nas refracionais. Mas o uso de lentes convencionais em anisometropias (axiais) equivale a prismações nos olhares fora dos centros ópticos (isto é, à direita, à esquerda, acima, abaixo), causando diplopia; daí a indicação, também nesses casos, de lentes de contato.

Na presbiopia, uma lente específica "para perto" (e.g., $33 \mathrm{~cm}$ ) diferente da que corrige a ametropia deve ser usada. Fala-se, então, em lentes "bifocais" em que, como o nome indica, há um "foco" para longe (correção da ametropia básica) e um para perto (para suprir a falta da acomodação). No entanto, em distâncias intermediárias não há adequação nem da lente "para longe" nem da "para perto". É, então, possível adicionar-se um segmento intermediário, para uma distância intemediária (por exemplo, $80 \mathrm{~cm}$ ), construindo-se uma lente "trifocal". Hoje, no entanto, já existem as lentes de poder dióptrico múltiplo, de acordo ao ponto em que elas são atravessadas pelo eixo visual (direção do olhar). São as lentes "multifocais".

Desde há alguns anos, popularizou-se o tratamento cirúrgico das ametropias, basicamente feito sobre a córnea, por alteração de sua curvatura anterior. Entre os vários tipos (ceratomileuse, ceratofacia, etc.) o mais simples e difundido é o das ceratotomias. Geralmente utilizado para a correção de miopias (ceratotomia radial), pode ser feito com anestesia tópica, mas não é isento de perigos: com as incisões feitas sobre a córnea e que, praticamente, tem profundidade equivalente a quase toda a sua espessura, são frequientes as perfurações (micro e macro, com saída de humor aquoso) por onde podem penetrar microorganismos, dando infecções, cuja progresão e acometimento de todo o olho (panoftalmite) levam à sua perda total. Nos melhores casos (sem infecções), o olho fica, pelo menos por meses, fragilizado, podendo romper-se a toques ou 
pressões que, antes, seriam normalmente suportadas. De resto, maus resultados (correção excessiva ou insuficiente, flutuações dióptricas no correr do dia, criação de astigmatismos de difícil correção, queixas de deslumbramentos à iluminação direta), não são de freqüência desprezível. Recentemente tem sido posta em prática a técnica de ablação de camadas internas da córnea, pelo uso do "excimer laser", com vantagens sobre a anterior. De qualquer modo, também sujeita a indicações específicas e com restrições dos tradicionalistas sobre as vantagens da relação entre riscos corridos e benefícios auferidos.

\section{PROGNÓSTICO}

Hipermetropias são mais comuns e maiores em crianças, tendendo a diminuir com a idade. Miopias, ao contrário, podem aparecer com a idade (freqüientemente na adolescência) e, ou aumentar com ela. As variações, entretanto, não são grandes (a não ser em casos de miopia "maligna") e, entre a segunda e a sexta década, quase nulas. Nas pessoas idosas, por adensamento do cristalino, há uma miopização absoluta ou relativa (diminuição de hipermetropia), um sinal prodrômico de sua opacificação (catarata).

É costumeira a referência de que a evolução de uma ametropia não fica afetada pela falta do uso de óculos, ou pelo uso deles. Contudo, há suposições de que o uso excessivo (e, ou continuado) da acomodação seja miopizante, o que, aliás, apresenta lógica. Daí a tradição de se hipocorrigir hipermétropes jovens e a de não se hipercorrigir míopes (embora hipocorreção de hipermétropes ou hipercorreção de míopes sejam análogas do ponto de vista óptico).

BICAS HEA. Ametropias and presbyopia. Medicina, Ribeirão Preto, 30: 20-26, jan./march 1997.

ABSTRACT: The optical system of a normal eye, with the basic characteristics and relationships of its components is defined for the distinction between emmetropia and axial or refractive ametropias (myopia and hyperopias). The techniques for the study of the optical state of the eyes (refractometry) are synthesized and other of their results (astigmatisms, anisometropias) are commented. It is also analysed the capability of the ocular focal power change (accommodation) and its progressive deterioration with the time (presbyopia). Symptoms and signs caused by the presbyopia and by the ametropias (reduction of visual acuity, ocular pains and irritations, headache, aversion to visual tasks, hordeola, strabismus, amblyopia, etc.), respective treatments and prognosis of the evolution are also considered.

UNITERMS: Myopia. Hyperopia. Astigmatism. Anisometropia. Accommodation, Ocular. Presbyopia.

\section{REFERÊNCIAS BIBLIOGRÁFICAS}

1 - BICAS HEA. Oftalmologia: Fundamentos. Ed. Contexto, São Paulo, 1991.
2 - BICAS HEA. Algumas considerações sobre as medidas de convergência, acomodação e relação $C_{A} / A$. Rev Latinoam Estrab 1: 68-87, 1976. 